\title{
Correction to: Spinal deformity and malocclusion association is not supported by high-quality studies: results from a systematic review of the literature
}

\author{
Francesco Langella ${ }^{1}$. Federico Fusini ${ }^{2} \cdot$ Gregorio Rossi $^{1}$ - Jorge Hugo Villafañe ${ }^{3} \cdot$ Nicola Migliaccio $^{1}$. \\ Sabrina Donzelli ${ }^{4} \cdot$ Pedro Berjano $^{1}$
}

Published online: 9 February 2019

(c) Springer-Verlag GmbH Germany, part of Springer Nature 2019

\section{Correction to: European Spine Journal https://doi.org/10.1007/s00586-019-05896-4}

Unfortunately, first name and family name in the author group were incorrectly swapped and published. The complete correct names of the author group are given below.

Francesco Langella

Federico Fusini

Gregorio Rossi

Jorge Hugo Villafañe

Nicola Migliaccio

Sabrina Donzelli
Pedro Berjano

The original article has been corrected.

Publisher's Note Springer Nature remains neutral with regard to jurisdictional claims in published maps and institutional affiliations.
The original article can be found online at https://doi.org/10.1007/ s00586-019-05896-4.

\section{Jorge Hugo Villafañe}

mail@villafane.it

Francesco Langella fralangell@gmail.com

Federico Fusini fusinif@hotmail.com

Gregorio Rossi

gregorio.rossi91@gmail.com

Nicola Migliaccio nicolamigliaccio@live.it

Sabrina Donzelli sabrina.donzelli@isico.it
Pedro Berjano

pberjano@gmail.com

IRCCS Istituto Ortopedico Galeazzi, Milan, Italy

2 Department of Orthopaedic and Traumatology, Orthopaedic and Trauma Centre, Azienda Ospedaliero Universitaria Città della Salute e della Scienza, University of Turin, via Zuretti 29, 10121 Turin, Italy

3 IRCCS Fondazione Don Carlo Gnocchi, Piazzale Morandi 6, Milan, Italy

4 ISICO - Italian Scientific Spine Institute, Milan, Italy 